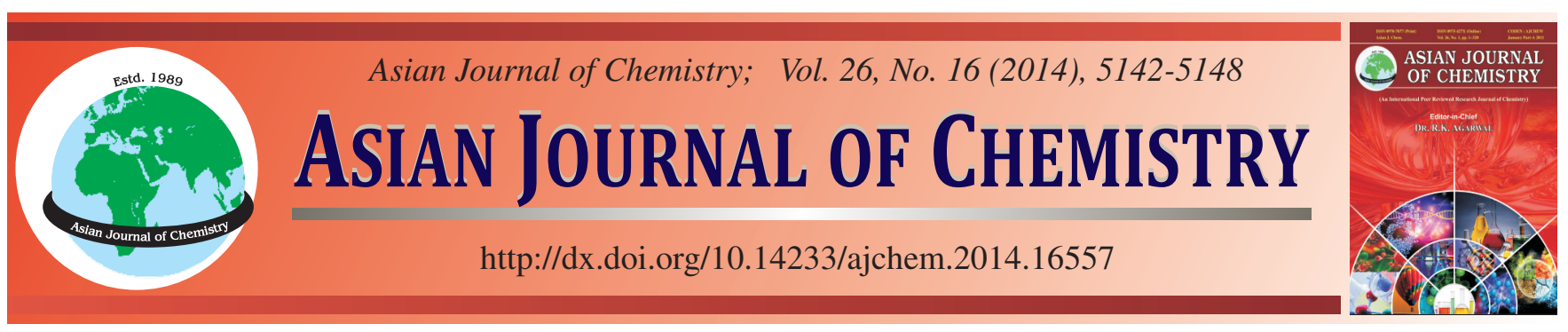

\title{
Experimental and Theoretical Studies of Ultrasonic Velocity in Ternary Liquid Mixtures of Methyl Benzoate, Cyclohexane and Alcohols at Different Temperatures
}

\author{
Umadevi Muthukrishnan ${ }^{1, *}$, Kesavasamy Ramasamy ${ }^{2}$, Palani Rathinasamy ${ }^{3}$ and Priya Nachimuthu Senniappan ${ }^{2}$
}

${ }^{1}$ Department of Physics, SVS College of Engineering, Coimbatore-642 109, India

${ }^{2}$ Department of Physics, Sri Ramakrishna Engineering College, Coimbatore-641 022, India

${ }^{3}$ Department of Physics, DDE, Annamalai University, Chidambaram-608 002, India

*Corresponding author: Fax: +91 422 2321332; E-mail: devuma55@gmail.com

Received: 21 October 2013;

Accepted: 16 April 2014;

Published online: 28 July 2014;

AJC-15649

Ultrasonic velocities of ternary liquid mixtures of methyl benzoate and cyclohexane with 1-propanol, 1-butanol, 1-pentanol and 1hexanol are measured using ultrasonic interferometer at 303, 308 and $313 \mathrm{~K}$ over the entire range of composition. Theoretical values of ultrasonic velocity have been evaluated at the three temperatures using Nomoto's relation, ideal mixture relation, impedance relation, Junjie's method, Rao's specific velocity relation and free length theory. Theoretical values are compared with the experimental values and $\mathrm{U}_{\text {exp }}{ }^{2} / \mathrm{U}_{\text {imx }}{ }^{2}$ is evaluated for non-ideality in the mixtures. A good agreement has been found between experimental and theoretical values of ultrasonic velocity. The relative applicability of these theories to the present systems has been checked and discussed. The results are explained in terms of molecular interactions occurring in these ternary liquid mixtures.

Keywords: Ultrasonic velocity, Methyl benzoate, Cyclohexane, Molecular interactions, Theoretical models.

\section{INTRODUCTION}

With the growth of scientific knowledge, it became increasingly necessary to specialize in the theoretical and experimental investigation by putting much effort. The material structures and contents may be achieved only if the scientist knows about theoretical background and technological aspect of the materials to be studied. Hence it is decided to evaluate the theoretical parameters of the selected components, when it is exposed to ultrasonic waves ${ }^{1}$.

Among the non-spectroscopic methods in the study of molecular interactions, the ultrasonic velocity measurement finds extensive applications owing to its ability of characterizing the physico-chemical behaviour of liquid systems from speed data. The ultrasonic velocity of liquid is fundamentally related to the binding forces between the atoms or the molecules. According to physical concept of liquid model, molecules in the liquid state are so loosely packed as to leave some free space in between them. The intermolecular free space and its dependent properties are related to intermolecular interactions and may reveal the some information regarding the interaction, which may be occurring when the liquids are mixed together ${ }^{2-4}$.

Several researchers ${ }^{3-10}$ carried out ultrasonic investigations on binary and ternary liquid mixtures and compared the experimental results with the theoretical relations of Nomoto ${ }^{11}$, Van
Dael and Vangeel ${ }^{12}$, impedance dependence ${ }^{13}$, Rao's specific velocity ${ }^{14}$ and Junjie's ${ }^{15}$ equations and the results are explained in terms of molecular interactions. An attempt has been made to compare the merits of relations for the ternary liquid mixtures investigated at different temperatures. The relative applicability of these theories to the present systems have been checked and discussed. Based on the deviation in $\mathrm{U}_{\exp }{ }^{2} / \mathrm{U}_{\mathrm{imx}}{ }^{2}$ and degree of intermolecular interaction or molecular association $(\alpha)$ the molecular interactions are studied. Theoretical values of ultrasonic velocities in ternary liquid mixtures were calculated using different theories and empirical relations. Comparison of theoretical values of ultrasonic velocities with those obtained experimentally in the present ternary liquid mixtures is expected to reveal the nature of interaction between the component molecules in the mixture. Such theoretical study is useful in building the comprehensive theoretical model for the liquid mixtures.

\section{EXPERIMENTAL}

All the chemicals used in the present work are AnalaR grade. The purity of the chemicals was ascertained by comparing their density, viscosity and ultrasonic velocity at 303, 308 and $313 \mathrm{~K}$ which agrees with the corresponding literature values. The mixtures of methyl benzoate + cyclohexane +1 propanol (system 1), methyl benzoate + cyclohexane +1 -butanol 
(system 2 ), methyl benzoate + cyclohexane +1 -pentanol (system 3 ) and methyl benzoate + cyclohexane +1 -hexanol (system 4) were prepared by weight. The mole fraction of the second component, cyclohexane $\left(\mathrm{x}_{2}=0.4\right)$ was kept constant, while the mole fractions of the remaining two $\left(\mathrm{x}_{1}, \mathrm{x}_{3}\right)$ were varied from 0.1 to 0.6 . The ultrasonic velocity was measured by a single crystal interferometer with a high degree of accuracy operating at a frequency of $3 \mathrm{MHz}$ (model F-05, with digital micrometer) at 303, 308 and $313 \mathrm{~K}$. The viscosity was measu-red by Ostwald's viscometer. An electronically operated constant temperature water bath is used to circulate water through the double walled measuring cell made up of steel containing the experimental solution at the desired temperature. Densities of the mixtures have been found by relative measurement method.

\section{Theory}

The following theories/relations are used for the prediction of ultrasonic velocity in the ternary liquid mixtures.

\section{Nomoto's relation $\left(\mathrm{U}_{\mathrm{NR}}\right)^{11}$}

$$
U_{N R}=\left[\frac{X_{1} R_{1}+X_{2} R_{2}+X_{3} R_{3}}{X_{1} V_{1}+X_{2} V_{2}+X_{3} V_{3}}\right]^{3}
$$

where $R_{i}$ is molar sound velocity and $V_{i}$ is molar volume. $X_{i}$ is the mole fraction.

Molar sound velocity

$$
\mathrm{R}_{1}=\frac{\mathrm{m}_{1}}{\mathrm{~d}_{1}} \mathrm{U}_{1}^{1 / 3} ; \mathrm{R}_{2}=\frac{\mathrm{m}_{2}}{\mathrm{~d}_{2}} \mathrm{U}_{2}^{1 / 3} ; \mathrm{R}_{3}=\frac{\mathrm{m}_{3}}{\mathrm{~d}_{3}} \mathrm{U}_{3}^{1 / 3}
$$

Molar volume

$$
\mathrm{V}_{1}=\frac{\mathrm{m}_{1}}{\mathrm{~d}_{1}} ; \mathrm{V}_{2}=\frac{\mathrm{m}_{2}}{\mathrm{~d}_{2}} ; \mathrm{V}_{3}=\frac{\mathrm{m}_{3}}{\mathrm{~d}_{3}}
$$

$\mathrm{m}_{1}, \mathrm{~m}_{2}$ and $\mathrm{m}_{3}$ are the molecular weight and $\mathrm{d}_{1}, \mathrm{~d}_{2}$ and $\mathrm{d}_{3}$ are the density of the component liquid. $\mathrm{U}_{1}, \mathrm{U}_{2}$ and $\mathrm{U}_{3}$ are the ultrasonic velocity of the pure liquids.

Van Dael relation (ideal mixtures relation): Van Dael and Vangeel ${ }^{12}$ suggested the following relation for the measurement of velocity of sound

$$
\frac{1}{X_{1} M_{1}+X_{2} M_{2}+X_{3} M_{3}} \cdot \frac{1}{U_{\text {Id.mix }}^{2}}=\frac{X_{1}}{M_{1} U_{1}}+\frac{X_{2}}{M_{2} U_{2}}+\frac{X_{3}}{M_{3} U_{3}} \text { (2) }
$$

where $U_{\text {id.mix }}$ is the ideal mixture ultrasonic velocity in liquid mixture. $\mathrm{X}_{\mathrm{i}}$ is the mole fraction, $\mathrm{M}_{\mathrm{i}}$ is the molar mass and $\mathrm{U}_{\mathrm{i}}$ is ultrasonic velocity.

Impedance relation (IMP) ${ }^{\mathbf{1 3}}$ : Product of ultrasonic velocity $(\mathrm{U})$ and density $(\rho)$ of the mixture is termed as acoustic impedance $(\mathrm{Z})$ of the mixture. Hence the sound velocity in the mixture can be predicted from the knowledge of acoustic impedance and the density of the pure components.

$$
\mathrm{U}_{\mathrm{IMP}}=\left[\frac{\mathrm{X}_{1} \mathrm{Z}_{1}+\mathrm{X}_{2} \mathrm{Z}_{2}+\mathrm{X}_{3} \mathrm{Z}_{3}}{\mathrm{X}_{1} \rho_{1}+\mathrm{X}_{2} \rho_{2}+\mathrm{X}_{3} \rho_{3}}\right]
$$

where $x_{i}$, is the mole fraction, $\rho_{i}$ the density of the mixture and $\mathrm{Z}_{\mathrm{i}}$ is the acoustic impedance.
Junjie's method (JM) ${ }^{15}$

$\mathrm{U}_{\mathrm{JM}}=\left[\frac{\mathrm{X}_{1} \mathrm{~V}_{1}+\mathrm{X}_{2} \mathrm{~V}_{2}+\mathrm{X}_{3} \mathrm{~V}_{3}}{\left(\mathrm{X}_{1} \mathrm{~m}_{1}+\mathrm{X}_{2} \mathrm{~m}_{2}+\mathrm{X}_{3} \mathrm{~m}_{3}\right)^{1 / 2}}\right] \cdot\left[\frac{\mathrm{X}_{1} \mathrm{~V}_{1}}{\mathrm{~d}_{1} \mathrm{U}_{1}^{2}}+\frac{\mathrm{X}_{2} \mathrm{~V}_{2}}{\mathrm{~d}_{2} \mathrm{U}_{2}^{2}}+\frac{\mathrm{X}_{3} \mathrm{~V}_{3}}{\mathrm{~d}_{3} \mathrm{U}_{3}^{2}}\right]^{-1 / 2}$

$\mathrm{X}_{\mathrm{i}}$ is the mole fraction, $\mathrm{d}_{\mathrm{i}}$ is the density, $\mathrm{U}_{\mathrm{i}}$ is ultrasonic velocity, $\mathrm{m}_{\mathrm{i}}$ is the molar mass and $\mathrm{V}_{\mathrm{i}}$ is the molar volume.

\section{Rao's specific sound velocity $(\mathrm{UR})^{14}$}

$$
\mathrm{U}_{\mathrm{R}}=\left(\sum \mathrm{x}_{\mathrm{i}} \mathrm{r}_{\mathrm{i}} \mathrm{d}\right)^{3}
$$

where $r_{i}=\frac{U_{i}^{1 / 3}}{d_{i}}, x_{i}$ is the mole fraction, $U_{i}$ is the ultrasonic velocity, $d$ the density of the mixture.

\section{Free length theory (FLT) ${ }^{26}$}

$$
\mathrm{U}_{\mathrm{FLT}}=\frac{\kappa}{\mathrm{L}_{\mathrm{f} \text { mix }} \mathrm{d}_{\text {expt }}^{1 / 2}}
$$

where $\mathrm{k}$ is the Boltzmann constant, $\mathrm{d}$ is the density and $\mathrm{L}_{\text {mix }}$

$$
=2\left[\frac{\mathrm{V}_{\mathrm{m}}-\left(\mathrm{X}_{1} \mathrm{~V}_{01}+\mathrm{X}_{2} \mathrm{~V}_{02}+\mathrm{X}_{3} \mathrm{~V}_{03}\right)}{\mathrm{X}_{1} \mathrm{Y}_{1}+\mathrm{X}_{2} \mathrm{Y}_{2}+\mathrm{X}_{3} \mathrm{Y}_{3}}\right]
$$

$\mathrm{X}_{\mathrm{i}}$ is the mole fraction

Molar volume at absolute zero is given by

$$
\mathrm{V}_{01}=\mathrm{V}_{1} \frac{\mathrm{U}_{1}}{\mathrm{U}_{\alpha}} ; \quad \mathrm{V}_{02}=\mathrm{V}_{2} \frac{\mathrm{U}_{2}}{\mathrm{U}_{\alpha}} ; \quad \mathrm{V}_{03}=\mathrm{V}_{3} \frac{\mathrm{U}_{3}}{\mathrm{U}_{\alpha}}
$$

Surface area per mole

$$
\mathrm{Y}_{1}=\frac{2\left(\mathrm{~V}_{1}-\mathrm{V}_{01}\right)}{\mathrm{L}_{\mathrm{f}_{1}}}
$$

$\mathrm{U}_{\mathrm{i}}$ is the ultrasonic velocity

\section{RESULTS AND DISCUSSION}

Experimental and computed ultrasonic velocity using eqn. 1-6 and their percentage relative deviation values for the ternary systems at 303, 308 and $313 \mathrm{~K}$ are given in Tables 1-8. The predictive abilities of various ultrasonic theories depend upon the strength of the interaction prevailing in a system. These theories generally fail to predict accurately the ultrasonic velocities where strong interactions supposed to exist and the average absolute percentage relative deviation is small in systems where the interactions are less or nil. The theoretically found ultrasonic velocities of liquid mixtures reveal that Nomoto's relation shows better agreement than the other relations.

The measurements of ultrasonic velocity in solutions formed by liquid components reveals the degree of deviation from ideality whenever there are interactions among the component molecules. The deviations have been used to gain insight into nature and degree of interactions among the interacting systems. In the case of liquid mixtures the data on composition dependency of ultrasonic velocity help to understand the nature of molecular interactions in terms of some physical parameters.

It can be seen from Tables 1, 3, 5 and 7 that the theoretical values of ultrasonic velocity calculated shows deviation from experimental values. The limitations and approximation 


\begin{tabular}{ccccccccc}
\hline $\mathrm{X}_{1}$ & $\mathrm{X}_{3}$ & $\mathrm{U}_{\mathrm{EXP}}$ & $\mathrm{U}_{\mathrm{NR}}$ & $\mathrm{U}_{\mathrm{IMP}}$ & $\mathrm{U}_{\mathrm{J}}$ & $\mathrm{U}_{\mathrm{R}}$ & $\mathrm{U}_{\mathrm{IMR}}$ & $\mathrm{U}_{\mathrm{FLT}}$ \\
\hline & & & & $303 \mathrm{~K}$ & & & & \\
\hline 0.5164 & 0.1396 & 1278.6 & 1278.1 & 1277.2 & 1279.9 & 1273.3 & 1275.5 & 1277.6 \\
0.4428 & 0.2107 & 1246.1 & 1245.6 & 1244.7 & 1247.4 & 1240.8 & 1243.0 & 1245.1 \\
0.3692 & 0.3028 & 1231.5 & 1231.0 & 1230.1 & 1232.8 & 1226.2 & 1228.4 & 1230.5 \\
0.2955 & 0.4297 & 1218.6 & 1218.1 & 1217.2 & 1219.9 & 1213.3 & 1215.5 & 1217.6 \\
0.1479 & 0.5046 & 1190.4 & 1189.9 & 1189.0 & 1191.7 & 1185.1 & 1187.3 & 1189.4 \\
0.0740 & 0.5805 & 1174.8 & 1174.3 & 1173.4 & 1176.1 & 1169.5 & 1171.7 & 1173.8 \\
\hline & & & & $308 \mathrm{~K}$ & & & & 1253.4 \\
\hline 0.5164 & 0.1396 & 1256.4 & 1255.9 & 1255.0 & 1257.7 & 1251.2 & 1255.4 \\
0.4428 & 0.2107 & 1220.2 & 1219.7 & 1218.8 & 1221.5 & 1215.0 & 1217.2 & 1219.2 \\
0.3692 & 0.3028 & 1208.1 & 1207.6 & 1206.7 & 1209.4 & 1202.9 & 1205.1 & 1207.1 \\
0.2955 & 0.4297 & 1197.6 & 1197.1 & 1196.2 & 1198.9 & 1192.4 & 1194.6 & 1196.6 \\
0.1479 & 0.5046 & 1177.2 & 1176.7 & 1175.8 & 1178.5 & 1172.0 & 1174.2 & 1176.2 \\
0.0740 & 0.5805 & 1148.4 & 1147.9 & 1147.0 & 1149.7 & 1143.2 & 1145.4 & 1147.4 \\
\hline & & & $313 \mathrm{~K}$ & & & & \\
\hline 0.5164 & 0.1396 & 1227.1 & 1226.6 & 1225.7 & 1228.4 & 1221.9 & 1224.1 & 1226.1 \\
0.4428 & 0.2107 & 1207.1 & 1206.6 & 1205.7 & 1208.4 & 1201.9 & 1204.1 & 1206.1 \\
0.3692 & 0.3028 & 1198.8 & 1198.3 & 1197.4 & 1200.1 & 1193.6 & 1195.8 & 1197.8 \\
0.2955 & 0.4297 & 1181.4 & 1180.9 & 1180.0 & 1182.7 & 1176.2 & 1178.4 & 1180.4 \\
0.1479 & 0.5046 & 1148.4 & 1147.9 & 1147.0 & 1149.7 & 1143.2 & 1145.4 & 1147.4 \\
0.0740 & 0.5805 & 1118.2 & 1117.7 & 1116.8 & 1119.5 & 1113.0 & 1115.2 & 1117.2 \\
\hline
\end{tabular}

TABLE-2

PERCENTAGE DEVIATION BETWEEN EXPERIMENTAL AND THEORETICAL VALUES OF VELOCITY $\left(\mathrm{m} \mathrm{s}^{-1}\right)$ FOR SYSTEM I AT DIFFERENT TEMPERATURES

\begin{tabular}{|c|c|c|c|c|c|c|c|}
\hline $\mathrm{X}_{1}$ & $X_{3}$ & $\% \mathrm{U}_{\mathrm{NR}}$ & $\% \mathrm{U}_{\mathrm{IMP}}$ & $\% \mathrm{U}_{\mathrm{J}}$ & $\% \mathrm{U}_{\mathrm{R}}$ & $\% \mathrm{U}_{\mathrm{IMR}}$ & $\% \mathrm{U}_{\mathrm{FLT}}$ \\
\hline \multicolumn{8}{|c|}{$303 \mathrm{~K}$} \\
\hline 0.5164 & 0.1396 & -0.039 & -0.109 & 0.102 & -0.415 & -0.242 & -0.078 \\
\hline 0.4428 & 0.2107 & -0.040 & -0.112 & 0.104 & -0.425 & -0.249 & -0.080 \\
\hline 0.3692 & 0.3028 & -0.041 & -0.114 & 0.106 & -0.430 & -0.252 & -0.081 \\
\hline 0.2955 & 0.4297 & -0.041 & -0.115 & 0.107 & -0.435 & -0.254 & -0.082 \\
\hline 0.1479 & 0.5046 & -0.042 & -0.118 & 0.109 & -0.445 & -0.260 & -0.084 \\
\hline 0.0740 & 0.5805 & -0.043 & -0.119 & 0.111 & -0.451 & -0.264 & -0.085 \\
\hline \multicolumn{8}{|c|}{$308 \mathrm{~K}$} \\
\hline 0.5164 & 0.1396 & -0.040 & -0.111 & 0.103 & -0.414 & -0.239 & -0.080 \\
\hline 0.4428 & 0.2107 & -0.041 & -0.115 & 0.107 & -0.426 & -0.246 & -0.082 \\
\hline 0.3692 & 0.3028 & -0.041 & -0.116 & 0.108 & -0.430 & -0.248 & -0.083 \\
\hline 0.2955 & 0.4297 & -0.042 & -0.117 & 0.109 & -0.434 & -0.251 & -0.084 \\
\hline 0.1479 & 0.5046 & -0.042 & -0.119 & 0.110 & -0.442 & -0.255 & -0.085 \\
\hline 0.0740 & 0.5805 & -0.044 & -0.122 & 0.113 & -0.453 & -0.261 & -0.087 \\
\hline 0.5164 & 0.1396 & -0.041 & -0.114 & 0.106 & -0.424 & -0.244 & -0.081 \\
\hline 0.4428 & 0.2107 & -0.041 & -0.116 & 0.108 & -0.431 & -0.249 & -0.083 \\
\hline 0.3692 & 0.3028 & -0.042 & -0.117 & 0.108 & -0.434 & -0.250 & -0.083 \\
\hline 0.2955 & 0.4297 & -0.042 & -0.119 & 0.110 & -0.440 & -0.254 & -0.085 \\
\hline 0.1479 & 0.5046 & -0.044 & -0.122 & 0.113 & -0.453 & -0.261 & -0.087 \\
\hline 0.0740 & 0.5805 & -0.045 & -0.125 & 0.116 & -0.465 & -0.268 & -0.089 \\
\hline
\end{tabular}

incorporated in these theories are responsible for the deviations of theoretical values from experimental values. In Nomoto's theory, it is supposed that the volume does not change on mixing. But on mixing three liquids, the interaction between the molecules of the liquids takes place because of the presence of various types of forces such as hydrogen bonding, dipoledipole, dispersive forces, charge transfer and dipole-induced dipole interactions. The deviations of experimental values from theoretical values calculated using Van Dael and Vangeel equation might be due to the compressibility of the component liquids in the present mixture. The deviations of experimental values and values calculated from impedance relation and Rao's relation imply non-additivity of acoustic impedance and Rao's velocity in the liquid mixture. Large deviations are observed in case of Junjie's relation. Thus, the observed deviation of theoretical values of velocity from the experimental values shows that the molecular interactions are taking place ${ }^{16-18}$ between the unlike molecules in the liquid mixture. On increasing the temperature, the ultrasonic velocity values decrease in the ternary liquid mixture. This is probably due to the fact that the thermal energy activates the molecule, which would increase the rate of association of unlike molecules ${ }^{19}$. Similar kinds of results were obtained by earlier workers ${ }^{20-25}$. The ratio $\mathrm{U}_{\exp }^{2} / \mathrm{U}_{\mathrm{IMR}}{ }^{2}$ is used to measure the non-ideality in 
liquid mixtures, especially in those cases where the properties other than sound velocity are not known.

It is observed from the Tables 1, 3, 5 and 7 that Nomoto's relation predicts a good agreement of sound velocity with the experimental values in ternary mixtures all the systems. The ideal mixture relation (IMR) yields a fair estimation of sound velocity for system III and system IV whereas a poor agreement for the other system. Impedance dependence value closely follows the experimental value in system III. It also estimates the sound velocity values in systems I \& II to a certain degree of accuracy. The collision factor model of sound velocity confirms well with the experiment in ternary system of system I. It fails to confirm with the values of system III whereas the system (I, II, IV) is better compared to the above said systems. Thus from the comparison of experimental velocity values with theoretical models, it is clear that the collision factor theory is best suited for system I and II and impedance dependence relation for system IV. The percentage of deviation of the theoretical ultrasonic velocity values from the experimental values are shown in Tables 2, 4, 6 and 8. We infer from Tables 2, 4, 6 and 8 that for all the systems, the theoretical ultrasonic velocity values based on Nomoto relation and free length

TABLE-3

EXPERIMENTAL AND THEORETICAL VALUES OF VELOCITY $\left(\mathrm{m} \mathrm{s}^{-1}\right)$ FOR SYSTEM II AT DIFFERENT TEMPERATURES

\begin{tabular}{|c|c|c|c|c|c|c|c|c|}
\hline$X_{1}$ & $X_{3}$ & $\mathrm{U}_{\mathrm{EXP}}$ & $\mathrm{U}_{\mathrm{NR}}$ & $\mathrm{U}_{\mathrm{IMP}}$ & $\mathrm{U}_{\mathrm{J}}$ & $\mathrm{U}_{\mathrm{R}}$ & $\mathrm{U}_{\mathrm{IMR}}$ & $\mathrm{U}_{\mathrm{FLT}}$ \\
\hline \multicolumn{9}{|c|}{$303 \mathrm{~K}$} \\
\hline 0.5164 & 0.1396 & 1361.6 & 1361.1 & 1360.2 & 1362.9 & 1356.5 & 1358.6 & 1360.6 \\
\hline 0.4428 & 0.2107 & 1295.6 & 1295.1 & 1294.2 & 1296.9 & 1290.5 & 1292.6 & 1294.6 \\
\hline 0.3692 & 0.3028 & 1256.1 & 1255.6 & 1254.7 & 1257.4 & 1251.0 & 1253.1 & 1255.1 \\
\hline 0.2955 & 0.4297 & 1224.3 & 1223.8 & 1222.9 & 1225.6 & 1219.2 & 1221.3 & 1223.3 \\
\hline 0.1479 & 0.5046 & 1187.7 & 1187.2 & 1186.3 & 1189.0 & 1182.6 & 1184.7 & 1186.7 \\
\hline 0.0740 & 0.5805 & 1046.2 & 1045.7 & 1044.8 & 1047.5 & 1041.1 & 1043.2 & 1045.2 \\
\hline \multicolumn{9}{|c|}{$308 \mathrm{~K}$} \\
\hline 0.5164 & 0.1396 & 1338.2 & 1337.7 & 1336.8 & 1339.5 & 1333.1 & 1335.2 & 1337.2 \\
\hline 0.4428 & 0.2107 & 1244.1 & 1243.6 & 1242.7 & 1245.4 & 1239.0 & 1241.1 & 1243.1 \\
\hline 0.3692 & 0.3028 & 1194.9 & 1194.4 & 1193.5 & 1196.2 & 1189.8 & 1191.9 & 1193.9 \\
\hline 0.2955 & 0.4297 & 1193.5 & 1193.0 & 1192.1 & 1194.8 & 1188.4 & 1190.5 & 1192.5 \\
\hline 0.1479 & 0.5046 & 1172.2 & 1171.7 & 1170.8 & 1173.5 & 1167.1 & 1169.2 & 1171.2 \\
\hline 0.0740 & 0.5805 & 1010.9 & 1010.4 & 1009.5 & 1012.2 & 1005.8 & 1007.9 & 1009.9 \\
\hline \multicolumn{9}{|c|}{$313 \mathrm{~K}$} \\
\hline 0.5164 & 0.1396 & 1316.1 & 1315.6 & 1314.7 & 1317.4 & 1311.0 & 1313.1 & 1315.1 \\
\hline 0.4428 & 0.2107 & 1226.1 & 1225.6 & 1224.7 & 1227.4 & 1221.0 & 1223.1 & 1225.1 \\
\hline 0.3692 & 0.3028 & 1184.1 & 1183.6 & 1182.7 & 1185.4 & 1179.0 & 1181.1 & 1183.1 \\
\hline 0.2955 & 0.4297 & 1178.2 & 1177.7 & 1176.8 & 1179.5 & 1173.1 & 1175.2 & 1177.2 \\
\hline 0.1479 & 0.5046 & 1127.8 & 1127.3 & 1126.4 & 1129.1 & 1122.7 & 1124.8 & 1126.8 \\
\hline 0.0740 & 0.5805 & 986.3 & 985.8 & 984.9 & 987.6 & 981.2 & 983.3 & 985.3 \\
\hline
\end{tabular}

TABLE-4

PERCENTAGE DEVIATION BETWEEN EXPERIMENTAL AND THEORETICAL VALUES OF VELOCITY $\left(\mathrm{m} \mathrm{s}^{-1}\right)$ FOR SYSTEM II AT DIFFERENT TEMPERATURES

\begin{tabular}{|c|c|c|c|c|c|c|c|}
\hline $\mathrm{X}_{1}$ & $\mathrm{X}_{3}$ & $\% \mathrm{U}_{\mathrm{NR}}$ & $\% \mathrm{U}_{\mathrm{IMP}}$ & $\% \mathrm{U}_{\mathrm{J}}$ & $\% \mathrm{U}_{\mathrm{R}}$ & $\% \mathrm{U}_{\mathrm{IMR}}$ & $\% \mathrm{U}_{\mathrm{FLT}}$ \\
\hline \multicolumn{8}{|c|}{$303 \mathrm{~K}$} \\
\hline 0.5164 & 0.1396 & -0.037 & -0.103 & 0.095 & -0.375 & -0.220 & 0.073 \\
\hline 0.4428 & 0.2107 & -0.039 & -0.108 & 0.100 & -0.394 & -0.232 & 0.077 \\
\hline 0.3692 & 0.3028 & -0.040 & -0.111 & 0.103 & -0.406 & -0.239 & 0.080 \\
\hline 0.2955 & 0.4297 & -0.041 & -0.114 & 0.106 & -0.417 & -0.245 & 0.082 \\
\hline 0.1479 & 0.5046 & -0.042 & -0.118 & 0.109 & -0.429 & -0.253 & 0.084 \\
\hline 0.0740 & 0.5805 & -0.048 & -0.134 & 0.124 & -0.487 & -0.287 & 0.096 \\
\hline \multicolumn{8}{|c|}{$308 \mathrm{~K}$} \\
\hline 0.5164 & 0.1396 & -0.037 & -0.105 & 0.097 & -0.381 & -0.224 & -0.075 \\
\hline 0.4428 & 0.2107 & -0.040 & -0.113 & 0.104 & -0.410 & -0.241 & -0.080 \\
\hline 0.3692 & 0.3028 & -0.042 & -0.117 & 0.109 & -0.427 & -0.251 & -0.084 \\
\hline 0.2955 & 0.4297 & -0.042 & -0.117 & 0.109 & -0.427 & -0.251 & -0.084 \\
\hline 0.1479 & 0.5046 & -0.043 & -0.119 & 0.111 & -0.435 & -0.256 & -0.085 \\
\hline 0.0740 & 0.5805 & -0.049 & -0.138 & 0.129 & -0.505 & -0.297 & -0.099 \\
\hline 0.5164 & 0.1396 & -0.038 & -0.106 & 0.099 & -0.388 & -0.228 & -0.076 \\
\hline 0.4428 & 0.2107 & -0.041 & -0.114 & 0.106 & -0.416 & -0.245 & -0.082 \\
\hline 0.3692 & 0.3028 & -0.042 & -0.118 & 0.110 & -0.431 & -0.253 & -0.084 \\
\hline 0.2955 & 0.4297 & -0.042 & -0.119 & 0.110 & -0.433 & -0.255 & -0.085 \\
\hline 0.1479 & 0.5046 & -0.044 & -0.124 & 0.115 & -0.452 & -0.266 & -0.089 \\
\hline 0.0740 & 0.5805 & -0.051 & -0.142 & 0.132 & -0.517 & -0.304 & -0.101 \\
\hline
\end{tabular}




\begin{tabular}{|c|c|c|c|c|c|c|c|c|}
\hline \multicolumn{9}{|c|}{$\begin{array}{l}\text { TABLE-5 } \\
\text { EXPERIMENTAL AND THEORETICAL VALUES OF VELOCITIES }\left(\mathrm{m} \mathrm{s}^{-1}\right) \text { OF } \\
\text { VELOCITY }\left(\mathrm{m} \mathrm{s}^{-1}\right) \text { FOR SYSTEM III AT DIFFERENT TEMPERATURES }\end{array}$} \\
\hline $\mathrm{X}_{1}$ & $\mathrm{X}_{3}$ & $\mathrm{U}_{\mathrm{EXP}}$ & $\mathrm{U}_{\mathrm{NR}}$ & $\mathrm{U}_{\mathrm{IMP}}$ & $\mathrm{U}_{\mathrm{J}}$ & $\mathrm{U}_{\mathrm{R}}$ & $\mathrm{U}_{\mathrm{IMR}}$ & $\mathrm{U}_{\mathrm{FLT}}$ \\
\hline \multicolumn{9}{|c|}{$303 \mathrm{~K}$} \\
\hline 0.5164 & 0.1396 & 1356.7 & 1356.2 & 1355.3 & 1358.0 & 1351.6 & 1353.7 & 1355.7 \\
\hline 0.4428 & 0.2107 & 1326.1 & 1325.6 & 1324.7 & 1327.4 & 1321.0 & 1323.1 & 1325.1 \\
\hline 0.3692 & 0.3028 & 1296.4 & 1295.9 & 1295.0 & 1297.7 & 1291.3 & 1293.4 & 1295.4 \\
\hline 0.2955 & 0.4297 & 1260.9 & 1260.4 & 1259.5 & 1262.2 & 1255.8 & 1257.9 & 1259.9 \\
\hline 0.1479 & 0.5046 & 1226.3 & 1225.8 & 1224.9 & 1227.6 & 1221.2 & 1223.3 & 1225.3 \\
\hline 0.0740 & 0.5805 & 1214.1 & 1213.6 & 1212.7 & 1215.4 & 1209.0 & 1211.1 & 1213.1 \\
\hline \multicolumn{9}{|c|}{$308 \mathrm{~K}$} \\
\hline 0.5164 & 0.1396 & 1315.3 & 1314.8 & 1313.9 & 1316.6 & 1310.2 & 1312.3 & 1314.3 \\
\hline 0.4428 & 0.2107 & 1290.1 & 1289.6 & 1288.7 & 1291.4 & 1285.0 & 1287.1 & 1289.1 \\
\hline 0.3692 & 0.3028 & 1253.7 & 1253.2 & 1252.3 & 1255.0 & 1248.6 & 1250.7 & 1252.7 \\
\hline 0.2955 & 0.4297 & 1234.2 & 1233.7 & 1232.8 & 1235.5 & 1229.1 & 1231.2 & 1233.2 \\
\hline 0.1479 & 0.5046 & 1212.1 & 1211.6 & 1210.7 & 1213.4 & 1207.0 & 1209.1 & 1211.1 \\
\hline 0.0740 & 0.5805 & 1205.3 & 1204.8 & 1203.9 & 1206.6 & 1200.2 & 1202.3 & 1204.3 \\
\hline \multicolumn{9}{|c|}{$313 \mathrm{~K}$} \\
\hline 0.5164 & 0.1396 & 1301.2 & 1300.7 & 1299.8 & 1302.5 & 1296.1 & 1298.2 & 1300.2 \\
\hline 0.4428 & 0.2107 & 1281.1 & 1280.6 & 1279.7 & 1282.4 & 1276.0 & 1278.1 & 1280.1 \\
\hline 0.3692 & 0.3028 & 1224.4 & 1223.9 & 1223.0 & 1225.7 & 1219.3 & 1221.4 & 1223.4 \\
\hline 0.2955 & 0.4297 & 1217.4 & 1216.9 & 1216.0 & 1218.7 & 1212.3 & 1214.4 & 1216.4 \\
\hline 0.1479 & 0.5046 & 1188.2 & 1187.7 & 1186.8 & 1189.5 & 1183.1 & 1185.2 & 1187.2 \\
\hline 0.0740 & 0.5805 & 1200.2 & 1199.7 & 1198.8 & 1201.5 & 1195.1 & 1197.2 & 1199.2 \\
\hline
\end{tabular}

TABLE-6

PERCENTAGE DEVIATION BETWEEN EXPERIMENTAL AND THEORETICAL VALUES OF VELOCITY $\left(\mathrm{m} \mathrm{s}^{-1}\right)$ FOR SYSTEM III AT DIFFERENT TEMPERATURES

\begin{tabular}{|c|c|c|c|c|c|c|c|}
\hline $\mathrm{X}_{1}$ & $\mathrm{X}_{3}$ & $\% \mathrm{U}_{\mathrm{NR}}$ & $\% \mathrm{U}_{\mathrm{IMP}}$ & $\% \mathrm{U}_{\mathrm{J}}$ & $\% \mathrm{U}_{\mathrm{R}}$ & $\% \mathrm{U}_{\mathrm{IMR}}$ & $\% \mathrm{U}_{\mathrm{FLT}}$ \\
\hline \multicolumn{8}{|c|}{$303 \mathrm{~K}$} \\
\hline 0.5164 & 0.1396 & -0.037 & -0.103 & 0.096 & -0.376 & -0.221 & -0.074 \\
\hline 0.4428 & 0.2107 & -0.038 & -0.106 & 0.098 & -0.385 & -0.226 & -0.075 \\
\hline 0.3692 & 0.3028 & -0.039 & -0.108 & 0.100 & -0.393 & -0.231 & -0.077 \\
\hline 0.2955 & 0.4297 & -0.040 & -0.111 & 0.103 & -0.404 & -0.238 & -0.079 \\
\hline 0.1479 & 0.5046 & -0.041 & -0.114 & 0.106 & -0.416 & -0.245 & -0.082 \\
\hline 0.0740 & 0.5805 & -0.041 & -0.115 & 0.107 & -0.420 & -0.247 & -0.082 \\
\hline \multicolumn{8}{|c|}{$308 \mathrm{~K}$} \\
\hline 0.5164 & 0.1396 & -0.038 & -0.106 & 0.099 & -0.388 & -0.228 & -0.076 \\
\hline 0.4428 & 0.2107 & -0.039 & -0.109 & 0.101 & -0.395 & -0.233 & -0.078 \\
\hline 0.3692 & 0.3028 & -0.040 & -0.112 & 0.104 & -0.407 & -0.239 & -0.080 \\
\hline 0.2955 & 0.4297 & -0.041 & -0.113 & 0.105 & -0.413 & -0.243 & -0.081 \\
\hline 0.1479 & 0.5046 & -0.041 & -0.116 & 0.107 & -0.421 & -0.248 & -0.083 \\
\hline 0.0740 & 0.5805 & -0.041 & -0.116 & 0.108 & -0.423 & -0.249 & -0.083 \\
\hline 0.5164 & 0.1396 & -0.038 & -0.108 & 0.100 & -0.392 & -0.231 & -0.077 \\
\hline 0.4428 & 0.2107 & -0.039 & -0.109 & 0.101 & -0.398 & -0.234 & -0.078 \\
\hline 0.3692 & 0.3028 & -0.041 & -0.114 & 0.106 & -0.417 & -0.245 & -0.082 \\
\hline 0.2955 & 0.4297 & -0.041 & -0.115 & 0.107 & -0.419 & -0.246 & -0.082 \\
\hline 0.1479 & 0.5046 & -0.042 & -0.118 & 0.109 & -0.429 & -0.252 & -0.084 \\
\hline 0.0740 & 0.5805 & -0.042 & -0.117 & 0.108 & -0.425 & -0.250 & -0.083 \\
\hline
\end{tabular}

theory gives less percentage of deviation than that of other theories. On the whole, all the theoretical models fairly predict that the ultrasonic velocities are reasonably close to the experimental values for the three ternary mixtures reported in this work, thus showing the validity of these theoretical models.

Percentage deviations of the ultrasonic velocity are both negative and positive. Such deviations indicate the non ideal behaviour of liquid mixtures. It is used as an important tool to measure the non-ideality in the mixtures, especially in those cases where the properties other than sound velocity are not known.

\section{Conclusion}

Ultrasonic velocities are calculated experimentally and the results are compared with the values calculated from various theories and relations. Ultrasonic method is a powerful probe for characterizing the physio-chemical properties and existence of molecular interaction in the liquid mixtures. In addition, ultrasonic velocity and the percentage deviation provide evidence of confirmation. It is concluded that the strong molecular interaction exists between the mixing components which may be due to the various types of forces such as hydrogen bonding, dipole-dipole, dispersive forces. Further the strength 
TABLE-7

\begin{tabular}{ccccccccc}
\hline $\mathrm{X}_{1}$ & $\mathrm{X}_{3}$ & $\mathrm{U}_{\mathrm{EXP}}$ & $\mathrm{U}_{\mathrm{NR}}$ & $\mathrm{U}_{\mathrm{IMP}}$ & $\mathrm{U}_{\mathrm{J}}$ & $\mathrm{U}_{\mathrm{R}}$ & $\mathrm{U}_{\mathrm{IMR}}$ & $\mathrm{U}_{\mathrm{FLT}}$ \\
\hline & & & & $303 \mathrm{~K}$ & & & & \\
\hline 0.5164 & 0.1396 & 1387.1 & 1386.6 & 1385.7 & 1388.4 & 1382.0 & 1384.1 & 1386.1 \\
0.4428 & 0.2107 & 1353.5 & 1353.0 & 1352.1 & 1354.8 & 1348.4 & 1350.5 & 1352.5 \\
0.3692 & 0.3028 & 1311.8 & 1311.3 & 1310.4 & 1313.1 & 1306.7 & 1308.8 & 1310.8 \\
0.2955 & 0.4297 & 1297.4 & 1296.9 & 1296.0 & 1298.7 & 1292.3 & 1294.4 & 1296.4 \\
0.1479 & 0.5046 & 1254.1 & 1253.6 & 1252.7 & 1255.4 & 1249.0 & 1251.1 & 1253.1 \\
0.0740 & 0.5805 & 1229.1 & 1228.6 & 1227.7 & 1230.4 & 1224.0 & 1226.1 & 1228.1 \\
\hline & & & & $308 \mathrm{~K}$ & & & & \\
\hline 0.5164 & 0.1396 & 1348.4 & 1347.9 & 1347.0 & 1349.7 & 1343.3 & 1345.4 & 1347.4 \\
0.4428 & 0.2107 & 1317.2 & 1316.7 & 1315.8 & 1318.5 & 1312.1 & 1314.2 & 1316.2 \\
0.3692 & 0.3028 & 1265.7 & 1265.2 & 1264.3 & 1267.0 & 1260.6 & 1262.7 & 1264.7 \\
0.2955 & 0.4297 & 1245.9 & 1245.4 & 1244.5 & 1247.2 & 1240.8 & 1242.9 & 1244.9 \\
0.1479 & 0.5046 & 1230.3 & 1229.8 & 1228.9 & 1231.6 & 1225.2 & 1227.3 & 1229.3 \\
0.0740 & 0.5805 & 1187.7 & 1187.2 & 1186.3 & 1189.0 & 1182.6 & 1184.7 & 1186.7 \\
\hline & & & $313 \mathrm{~K}$ & & & & \\
\hline 0.5164 & 0.1396 & 1313.1 & 1312.6 & 1311.7 & 1314.4 & 1308.0 & 1310.1 & 1312.1 \\
0.4428 & 0.2107 & 1297.4 & 1296.9 & 1296.0 & 1298.7 & 1292.3 & 1294.4 & 1296.4 \\
0.3692 & 0.3028 & 1248.3 & 1247.8 & 1246.9 & 1249.6 & 1243.2 & 1245.3 & 1247.3 \\
0.2955 & 0.4297 & 1234.5 & 1234.0 & 1233.1 & 1235.8 & 1229.4 & 1231.5 & 1233.5 \\
0.1479 & 0.5046 & 1200.3 & 1199.8 & 1198.9 & 1201.6 & 1195.2 & 1197.3 & 1199.3 \\
0.0740 & 0.5805 & 1166.5 & 1166.0 & 1165.1 & 1167.8 & 1161.4 & 1163.5 & 1165.5 \\
\hline
\end{tabular}

TABLE-8

PERCENTAGE DEVIATION BETWEEN EXPERIMENTAL AND THEORETICAL VALUES OF VELOCITY $\left(\mathrm{ms}^{-1}\right)$ FOR SYSTEM IV AT DIFFERENT TEMPERATURES

\begin{tabular}{|c|c|c|c|c|c|c|c|}
\hline $\mathrm{X}_{1}$ & $X_{3}$ & $\% \mathrm{U}_{\mathrm{NR}}$ & $\% \mathrm{U}_{\mathrm{IMP}}$ & $\% \mathrm{U}_{\mathrm{J}}$ & $\% \mathrm{U}_{\mathrm{R}}$ & $\% \mathrm{U}_{\mathrm{IMR}}$ & $\% \mathrm{U}_{\mathrm{FLT}}$ \\
\hline \multicolumn{8}{|c|}{$303 \mathrm{~K}$} \\
\hline 0.5164 & 0.1396 & -0.036 & -0.101 & 0.094 & -0.368 & -0.216 & -0.072 \\
\hline 0.4428 & 0.2107 & -0.037 & -0.103 & 0.096 & -0.377 & -0.222 & -0.074 \\
\hline 0.3692 & 0.3028 & -0.038 & -0.107 & 0.099 & -0.389 & -0.229 & -0.076 \\
\hline 0.2955 & 0.4297 & -0.039 & -0.108 & 0.100 & -0.393 & -0.231 & -0.077 \\
\hline 0.1479 & 0.5046 & -0.040 & -0.112 & 0.104 & -0.407 & -0.239 & -0.080 \\
\hline 0.0740 & 0.5805 & -0.041 & -0.114 & 0.106 & -0.415 & -0.244 & -0.081 \\
\hline \multicolumn{8}{|c|}{$308 \mathrm{~K}$} \\
\hline 0.5164 & 0.1396 & -0.037 & -0.104 & 0.096 & -0.378 & -0.222 & -0.074 \\
\hline 0.4428 & 0.2107 & -0.038 & -0.106 & 0.099 & -0.387 & -0.228 & -0.076 \\
\hline 0.3692 & 0.3028 & -0.040 & -0.111 & 0.103 & -0.403 & -0.237 & -0.079 \\
\hline 0.2955 & 0.4297 & -0.040 & -0.112 & 0.104 & -0.409 & -0.241 & -0.080 \\
\hline 0.1479 & 0.5046 & -0.041 & -0.114 & 0.106 & -0.415 & -0.244 & -0.081 \\
\hline 0.0740 & 0.5805 & -0.042 & -0.118 & 0.109 & -0.429 & -0.253 & -0.084 \\
\hline 0.5164 & 0.1396 & -0.038 & -0.107 & 0.099 & -0.388 & -0.228 & -0.076 \\
\hline 0.4428 & 0.2107 & -0.039 & -0.108 & 0.100 & -0.393 & -0.231 & -0.077 \\
\hline 0.3692 & 0.3028 & -0.040 & -0.112 & 0.104 & -0.409 & -0.240 & -0.080 \\
\hline 0.2955 & 0.4297 & -0.041 & -0.113 & 0.105 & -0.413 & -0.243 & -0.081 \\
\hline 0.1479 & 0.5046 & -0.042 & -0.117 & 0.108 & -0.425 & -0.250 & -0.083 \\
\hline 0.0740 & 0.5805 & -0.043 & -0.120 & 0.111 & -0.437 & -0.257 & -0.086 \\
\hline
\end{tabular}

of interaction tends to be weaker with rise in temperature due to weak intermolecular forces and thermal dispersive forces. It is understood from the results that out of all the theories and the relations discussed above, the Nomoto's relation provides the best results for all the systems.

\section{REFERENCES}

1. J. Thennarasu and G. Meenakshi, Int. Interdiscipl. Res. J., 1, 43 (2011).

2. N. Santhi, P. L. Sabarathinam, J. Madhumitha, G. Alamelumangai and M. Emayavaramban, Int. Lett. Chem. Phy. Astron., 2, 18 (2013).
3. A. Ali, Abida, A.K. Nain and S. Hyder, J. Pure Appl. Ultrason., 23, 73 (2001).

4. P.S. Naidu and K. Ravindra Prasad, J. Pure Appl. Ultrason, 24, 1824 (2002).

5. C.H. Srinivasu, K. Narendra and C.H. Kalpana, E-J. Chem., 8, 977 (2011).

6. A. Pal and H. Kumar, Indian J. Phys., 78, 1319 (2004).

7. G.V.R. Rao, A.V. Sarma, J.S.R. Krishna and C. Rambabu, J. Indian Pure Appl. Phys., 43, 345 (2005).

8. D. Saravana Kumar and D. Krishna Rao, J. Indian Pure Appl. Phys., 45, 210 (2007).

9. R. Uvarani and S. Punitha, E-J. Chem., 6(s1), 235 (2009).

10. S. Parveen, D. Shukla, S. Singh, K.P. Singh, M. Gupta and J.P. Shukla, Appl. Acoust., 70, 507 (2009). 
11. O. Nomoto, J. Phys. Soc. Jpn., 13, 1528 (1958).

12. W. Van Dael and E. Vangeel, Proc Int Conf on calorimetry and thermodynamics, Warasa, p. 555 (1955).

13. S. Baluja and P.H. Parsania, Asian J. Chem., 7, 417 (1995).

14. V.D. Gokhale and N.N. Bhagavan, Indian J. Pure Appl. Ultrason., 11, 21 (1989).

15. Z. Junjie, J. China Univ. Sci. Technol., 14, 298 (1984).

16. G.V. Rama Rao, P.B. Sandhya Sri, A. Viswanatha Sarma, C. Rambabu and J. Indian, Pure Appl. Phys., 45, 135 (2007).

17. K. Saravanaku, R. Baskaran and T.R. Kubendran, J. Appl. Sci., 10, 1616 (2010).

18. S. Anuradha, S. Prema and K. Rajagopal, J. Pure Appl. Ultrason., 27, 49 (2005).
19. N. Santhi, P.L. Sabarathinam, M.E. C. Gopi and C. Manivannan, E-J. Chem., 7, 648 (2010).

20. M. Rastogi, A. Awasthi, M. Gupta and J.P. Shukla, J. Indian Pure Appl. Phys., 40, 256 (2002)

21. P. Vasantharani, S. Muthu Shailaja, A.N. Kannappan and R. Ezhil Pavai, J. Appl. Sci., 8, 2329 (2008).

22 S. Babu, S.V.K. Sastry, H.S. Tiong and S.S. Sastry, E-J. Chem., 9, 2309 (2012).

23. G.R. Bedare, V.D. Bhandakkar and B.M. Suryavanshi, J. Chem. Pharm. Res., 4, 1028 (2012).

24. A. Ali and A.K. Nain, J. Pure Appl. Ultrason., 22, 10 (2000).

25. A. Ali, Abida, S. Hyder and A.K. Nain, Collect. Czech. Chem. Commun., 67, 1125 (2002). 